\title{
Protected Culture for Vegetable and Small Fruit Crops: Types of Structures ${ }^{1}$
}

\author{
Bielinski M. Santos, Gary Vallad, and Emmanuel A. Torres-Quezada²
}

\section{Classification of protective structures}

A protective structure is defined as any structure designed to modify the environment in which plants are grown. Protective structures, such as greenhouses, screen houses, and tunnels, are known worldwide as production systems for high-quality vegetable and fruit crops. Protective structures increase crop yield and quality by altering environmental factors, such as light, temperature, air humidity, wind, and/ or pest pressure. Manipulation of these environmental factors depends on the specific properties of the materials used on the roofs and sides of structures, as well as on the structure height, shape, and position. For instance, in regions located in northern latitudes, such as Canada and the Netherlands where season extension during the winter months is critical, greenhouses possess glass roofs and sides to preserve heat and maximize penetration of solar irradiation. However, in greenhouses and screen houses in tropical and subtropical climates, structures are made of flexible solid or porous plastic sheets that often reduce internal heat accumulation and favor passive ventilation.

Protective structures are classified in two main groups, according to their roof types: a) greenhouses or nonporous roof structures and b) screen/shade houses or porous-roof structures (Figure 1). A porous roof cover is generally defined as a material that greatly restricts water and gas

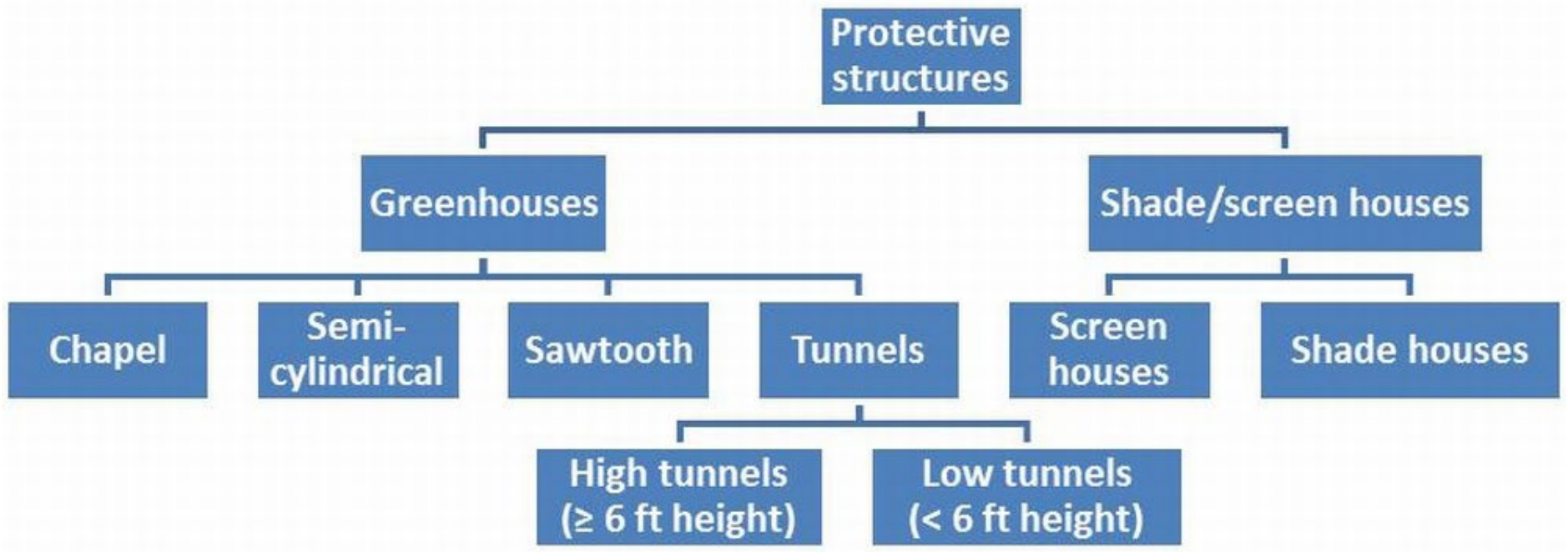

Figure 1. Protective structure classification according to roof type Credits: B. M. Santos and E. A. Torres-Quezada

1. This document is HS1224, one of a series of the Horticultural Sciences Department, UF/IFAS Extension. Original publication date July 2013. Visit the EDIS website at http://edis.ifas.ufl.edu.

2. Blelinski M. Santos, associate professor, Horticultural Sciences Department; Gary E. Vallad, associate professor, Plant Pathology Department; and Emmanuel A. Torres-Quezada, research assistant; UF/IFAS Gulf Coast Research and Education Center, Wimauma, FL 33598. 


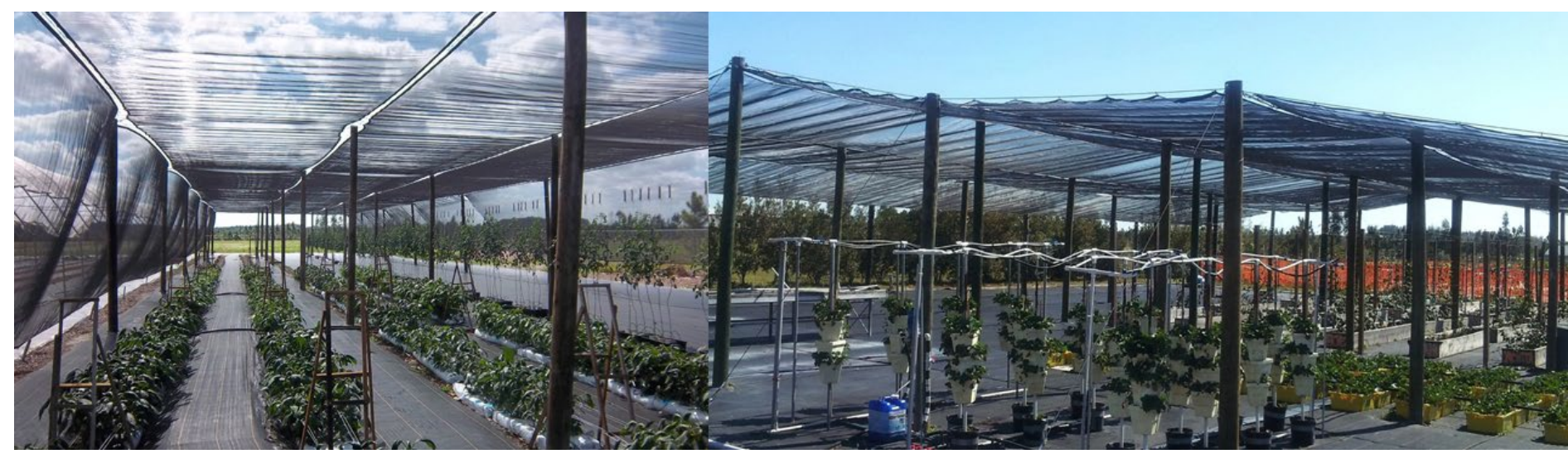

Figure 2. Shade houses for vegetable and small fruit production Credits: B. M. Santos

penetration through it. This does not include ventilation windows and openings on top of the structure. Examples of this type of roof include glass, plexiglass, and multilayer polyethylene sheets. Nonporous roof examples are saran nets and screen sheets.

Shade houses and screen houses are the predominant types of porous-roof structures. The main difference between them is the color and mesh of their nets. Shade houses are usually made of black, red, or blue covers, and they are designed to protect the crop from intense sunlight while decreasing temperature and air humidity under the structure (Figure 2). Screen houses protect crops from high winds and prevent entry of mites, thrips, and aphids. They are usually covered with white nets. The level of protection a screen house provides against arthropod pests is related to the mesh of the net used in the structure. Some disadvantages of screen houses are low air movement and high temperatures. The use of screen houses in subtropical and tropical areas may be limited during the rainy season because of the high incidence of physiological disorders and propagation of disease-causing pathogens. Both shade houses and screen houses have very low initial costs $(<$ $\left.\$ 0.50 / \mathrm{ft}^{2}\right)$ and maintenance.

\section{Chapel}

This permanent structure has a roof with two tilted surfaces, between $25^{\circ}$ and $45^{\circ}$, and is oriented according to wind speed and rainfall. It has either active or passive ventilation through the roof and sides. It's made of wood or steel and ranges in height from 12 to $20 \mathrm{ft}$ (Figure 3). Multi-chapel units are composed of single units attached to each other by rain gutters.

\section{Semi-cylindrical}

This permanent structure is usually made of steel and is as tall as the chapel type (Figure 3). It has semi-circular or semi-oval roofs supported on sides as low as $6 \mathrm{ft}$ high. This type of structure may have active or passive ventilation through the roof and sides.

\section{Sawtooth}

This permanent structure has one-sided roofs tilted between $25^{\circ}$ and $45^{\circ}$ with one window for ventilation opposite to the direction of the predominant winds. It is designed to maximize the recirculation of the air from inside to outside. The structure is made of wood or steel and ranges in height from 13 to $20 \mathrm{ft}$.

Greenhouses come in a variety of designs for vegetable and small fruit production and are classified according to their shape and height.

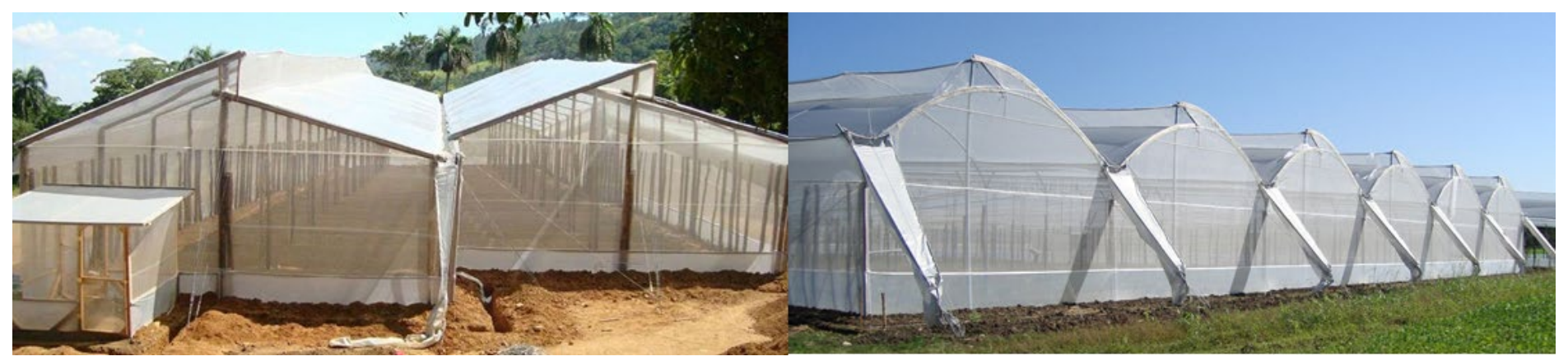

Figure 3. Multi-chapel (left) and semi-cylindrical (right) greenhouse units with passive ventilation on roofs Credits: B.M. Santos 


\section{Tunnels}

Tunnels are the low-cost version of greenhouses. They are nonpermanent structures with passive ventilation through the sides and ends and have reduced construction and maintenance costs. These structures can be moved from one place to another, which allows for rotating to new soils and avoiding pests, disease build-up, and nutrient depletion. The structure's height directly influences air and soil temperatures under plastic roof covers. Tunnels can be classified as low ( $<6 \mathrm{ft}$ high) or high ( $\geq 6 \mathrm{ft}$ high).

Low tunnels (also known as microtunnels) are small, simple, easily installed, and inexpensive. They are covered with a fine net or plastic film that provides temporary protection for the crop. Low tunnels are generally used to protect crops during initial growth stages, against adverse climatic conditions, and to exclude certain diseases and insects (Figure 4). They are usually constructed along the crop row with flexible arches or hoops made of plastic or metal to support the net or plastic film. They can be ventilated by moving the cover to the sides and securing it with hooks or ropes. Their height usually restricts personnel movement and machinery under the roof, but they can cover more than one crop row.

High tunnels are passively ventilated structures built with metal (e.g., galvanized steel or iron), plastic (e.g., polyvinyl chloride [PVC] pipes), or wood, which is usually covered with one or more layers of plastic film and anti-insect screen (Figure 4). Their height is generally between 10 and $16 \mathrm{ft}$, and they are recommended for indeterminate-growth cultivars, which cannot be grown under low tunnels. Their height also allows for personnel and large agricultural equipment, unlike low tunnels.

\section{Plastic covers for roofs}

Plastic roof covers for protective structures protect the crop against rain and wind, reduce or increase temperature and relative humidity, regulate light, and reduce the incidence of pests. Several characteristics of roof covers determine the degree to which a structure's internal environment is regulated.

\section{Color}

Different colors of plastic have different effects on plants. Most plastic covers are transparent, allowing light to penetrate. In tropical and subtropical areas, the amount of sunlight available usually surpasses the photosynthetic needs of the plants, which reflect the excess light as heat. Changing the roof color to white or gray causes it to reflect part of the light that reaches the roof surface, decreasing the temperature inside the structure. Opaque plastics reflect radiation out of the structure, decreasing temperature, but increasing shading. Excess shading induces etiolation ("stretching") of the plants and redistribution of carbohydrates because of competition for light between plants, likely decreasing fruit yield and quality. Sometimes an additional layer of shading can be added on top of the solid plastic roof or just inside the structure to change air temperature and/or diffuse light. For instance, adding a silver or gray saran layer outside the roof reduces temperature, whereas a red saran layer tends to enhance seed germination and early development.

\section{Density and resistance}

The density of the plastic roof affects temperature inside the structure. More rigid or heavier plastic needs more support to stay on top of the structure, creating artificial shadow that affects plants. At the same time, plastics must be resistant to potential wind and rain damage as well as to deformation from high and low temperatures.

\section{Additives}

Most plastic covers are composed of polyethylene chains and layers bonded together. Plastics for roofs often have

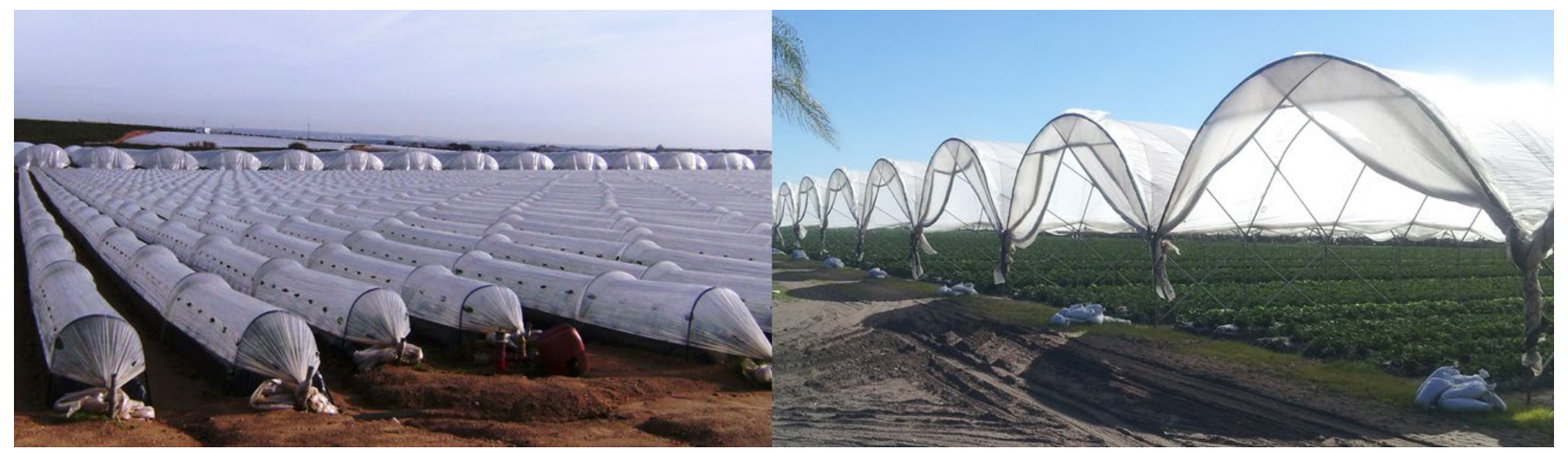

Figure 4. Low (left) and high (right) tunnels for vegetable and small fruit production Credits: B.M. Santos 
two layers of polyethylene. Temperature modification inside structures can be achieved by including additives, such as those that diffuse light and reflect ultraviolet radiation.

\section{Additional considerations for applying pesticides within protective structures}

As mandated by the U.S. Federal Insecticide, Fungicide and Rodenticide Act (FIFRA), it is unlawful to use any registered pesticide in a manner inconsistent with its labeling. Any language on the label that specifically prohibits or limits pesticide usage in a greenhouse environment must be followed. However, protective structures are quite diverse, and so growers must be mindful of what constitutes a greenhouse within state and federal laws. While the classification described here based on rooftops is a practical means for classifying production structures, many of these structures would not fall under the definition of a greenhouse as interpreted by the U.S. Environmental Protection Agency (US-EPA) for pesticide labeling. A greenhouse is defined within the Workers Protection Standard (40 CFR 170.3 ) as “....any operation engaged in the production of agricultural plants inside any structure or space that is enclosed with nonporous covering and that is of sufficient size to permit worker entry." Per the US-EPA interpretation of this definition (WPS 40 CFR Parts $156 \& 170$ Interpretive Policy), a structure is not considered a greenhouse with regard to pesticide applications if the structure is covered with a porous covering or has a nonporous roof with porous sidewalls. For the purpose of pesticide applications, structures that feature nonporous sides/panels for a significant portion of the structure that can be either removed, opened, or moved up or down would not be considered greenhouses as long as they are "open" and remain open during the pesticide application and during any applicable reentry interval. These removable openings do not include windows or doors (WPS 40 CFR Parts 156 \& 170 Interpretive Policy). 